\title{
Analysis on the Architectural Form of Zhushan Academy
}

\author{
Yuan Gao, Yuhan Dong \\ School of Architecture and Urban Planning, Huazhong University of Science and Technology, Wuhan, China \\ Email: 1505915147@qq.com
}

How to cite this paper: Gao, Y., \& Dong, Y. H. (2017). Analysis on the Architectural Form of Zhushan Academy. Art and Design Review, 5, 200-212.

https://doi.org/10.4236/adr.2017.53016

Received: April 4, 2017

Accepted: August 13, 2017

Published: August 16, 2017

Copyright (c) 2017 by authors and Scientific Research Publishing Inc. This work is licensed under the Creative Commons Attribution International License (CC BY 4.0).

http://creativecommons.org/licenses/by/4.0/ (c) (†) Open Access

\begin{abstract}
Based on its unique natural environment and human factors, the folk academies achieve rich construction wisdom. The adaption to local environment and the inheritance of regional culture is worth studying. Zhushan academy is a typical example in Anhui Province, China during the Ming and Qing Dynasties. The whole academy consists of educational buildings and the cultural garden. In this paper, the author starts from the case study of Zhushan academy and extracts suitable construction wisdom for modern educational architecture in order to provide some enlightening guidance for its construction.
\end{abstract}

\section{Keywords}

Traditional Folk Academy, Zhushan Academy, Architectural Form, Modern Educational Architecture, Enlightenment

\section{Introduction}

As a nongovernmental organization, an academy is a place for ancient Confucian (theory founded by Confucius) scholars to assemble, give lectures, collect books, study and go sightseeing. Zhushan academy is located in Anhui Province, which was a part of the ancient Huizhou State in China. The existing part of the academy is mostly original and well preserved.

\subsection{Location}

Zhushan academy is located on the east of Xiong Village (Figure 1), She County, Anhui Province, which is $6 \mathrm{~km}$ from the county. Its South-west is the Yan Village Ellora Caves and Yansi Town is on its west. Its exact location is $29^{\circ} 30^{\prime} 29^{\prime \prime} \mathrm{N}$ $30^{\circ} 9^{\prime} 10^{\prime \prime} \mathrm{N}, 118^{\circ} 4^{\prime} 40^{\prime \prime} \mathrm{E}-118^{\circ} 53^{\prime} 50^{\prime \prime} \mathrm{E}$. The Jian River flows from south to north, meandering through the central part of Xiong Village. Therefore, a platform is formed in this region. The rest part is mainly hilly area. A highway goes past the 


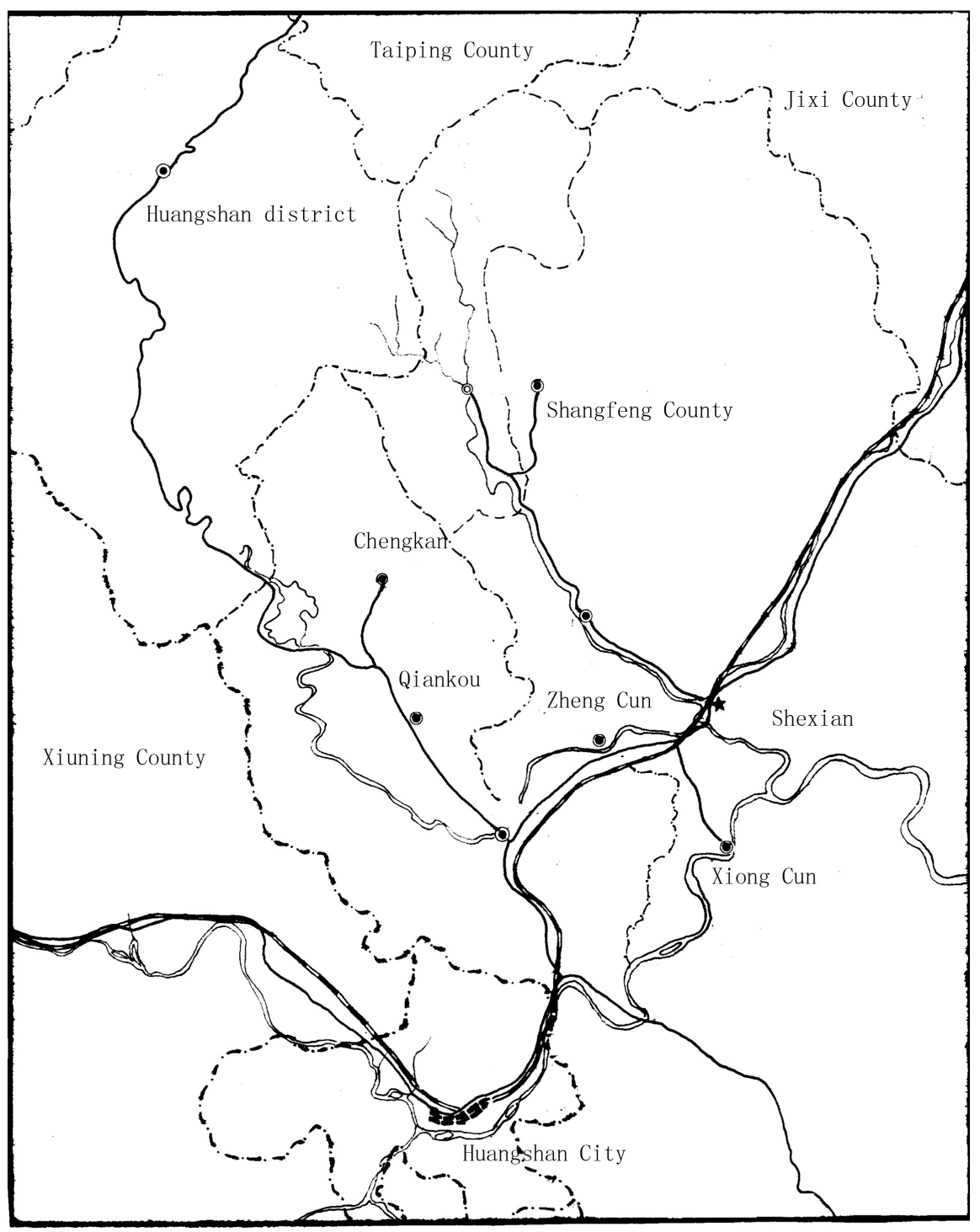

Figure 1. Location of Xiong village.

north part of the village with high accessibility. The highest temperature is about $40^{\circ} \mathrm{C}$ and the lowest temperature is $-12^{\circ} \mathrm{C}$.

\subsection{Natural and Human Environment}

Xiong Village is surrounded by low hills, with intact forest vegetation (mainly pines, firs and bamboos). The soil is mostly loess texture. Zhushan academy covers an area of more than $2000 \mathrm{~m}^{2}$. The academy faces hills and rivers with folk dwellings on its west.

The aborigines in the village were famous salt dealers with the family name Cao. There were 53 descendants who passed the imperial exam, which made the village full of the atmosphere of literature. There are still many historic sites in the village, such as Zhushan academy, archways (Figure 2), Ciguang Temple etc. There are more than ten ancient dwellings during the Ming and Qing Dynasties in the village as well. 


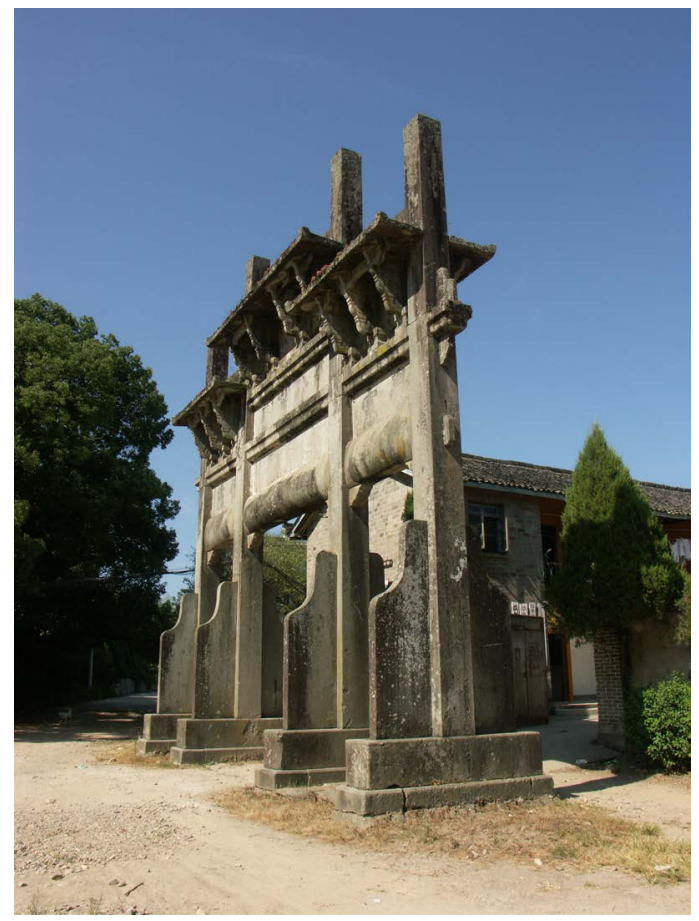

Figure 2. The archway.

\subsection{History of Zhushan Academy}

The academy was constructed from 1755 to 1759 in the Qianlong period. At the end of Qing Dynasty, the academy was transformed into a primary school. After liberation, the academy continued to be used as the Xiong Village Primary School. Therefore, most buildings were well preserved. In 1995, the primary school moved out. From then on, the buildings and the garden of the academy were better protected by the cultural relics administration section (Figure 3).

\section{The Architectural Form of Zhushan Academy}

The layout of the academy is rather subtle. The overall plan is a rectangle. The north-south distance is 86 meters and the east-west distance is 33 meters. The academy consists of two parts: educational buildings and the garden.

\subsection{Site Selection}

Influenced by the geomantic omen, the ancients in China cared about the site selection of academies a lot. The site is usually situated at the foot of a hill and facing the river, which is harmonious with nature. From Tang and Song Dynasties, the site selection of the villages in ancient Huizhou was based on the geomantic omen. People paid great attention to the concept of "water gap". The location of "water gap" is usually the stream outlet, stone dam, windbreak, village pavilion, public house or Wenchang Pavilion, so that the village can show its inculcation tradition and a safe, beautiful appearance (Chen, 2006). The site selection of Zhushan academy focuses on the natural environment a lot. The academy (Figure 4) is located "inside the water gap", next to the public house. 


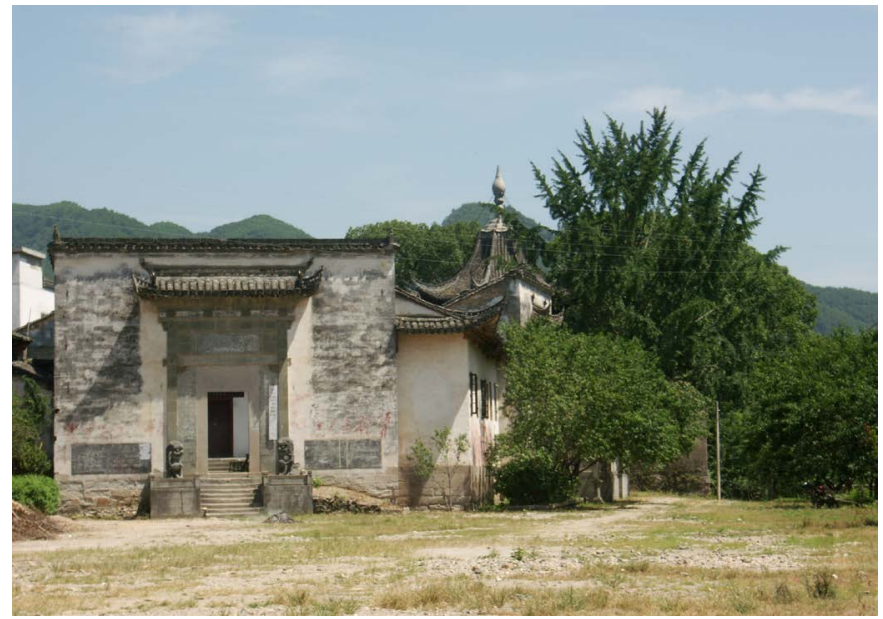

Figure 3. Overview of Zhushan academy.

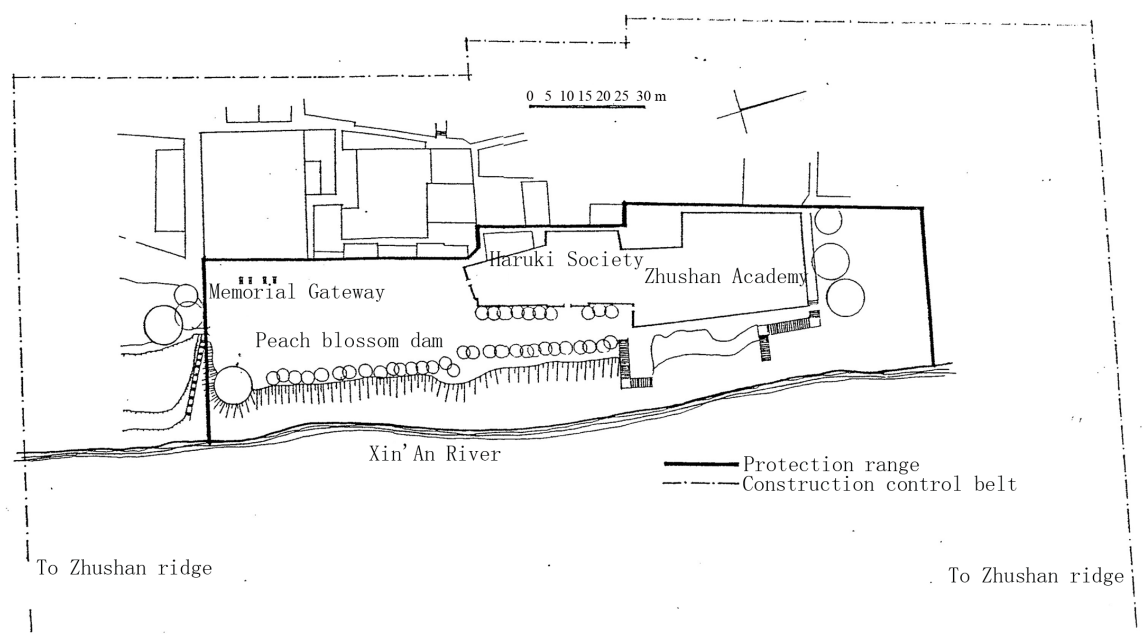

Figure 4. Site plan of the academy.

The site faces the open field and is far from the residential area, which creates an ideal environment for the academy.

\subsection{Layout}

The layout of Zhushan academy is a combination of regular and natural. As a synthesis of educational buildings and the garden, Zhushan academy can be divided into the south part and the north part (Figure 5).

The south part consists of the main educational buildings in the academy. The whole buildings adopts adopt the layout of axial symmetry. This type of layout is full of orderly rational beauty, which can create a solemn, dignified, peaceful and quiet environment. There are three east-west axises in the south part: The first axis is the lobby, isles, patio and the lecture hall. The second is the library, study, patio and kitchen. The third one is the Tiaofan Hall, Moxiang Hall and the peony garden. The lecture hall is the core building in this part. Other buildings such as the study and kitchen are arranged around it, tightly combined and non-interference. 


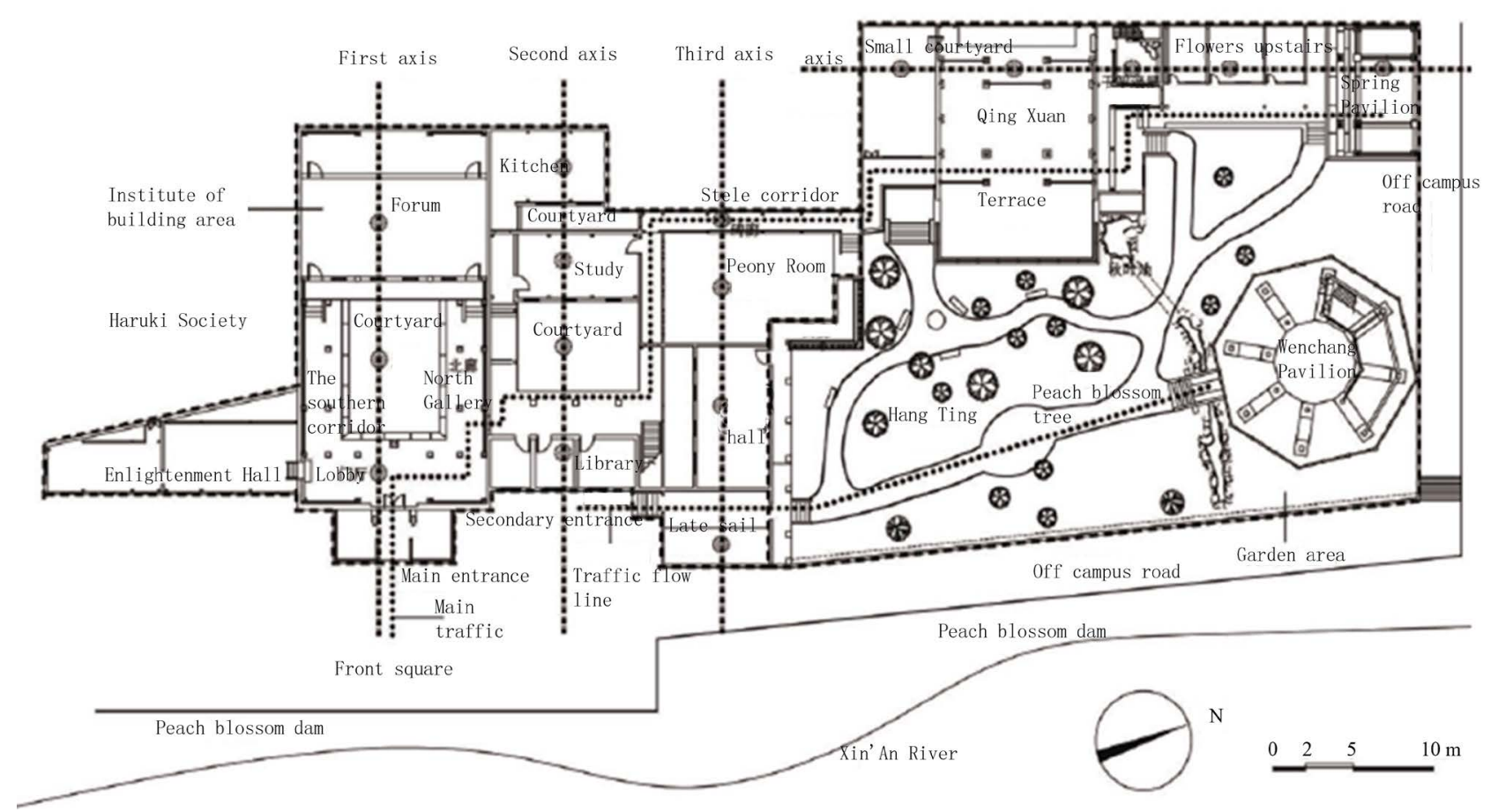

Figure 5. Plan of the academy.

The north part is the garden, which is a place for scholars to get together and exchange academic ideas. Qingkuang Hall, Baihua Toushang Building and Chunfeng Pavilion form the north-south axis of the garden. The axis, the isles and Tiaofan Hall enclose the main area of the garden-Osmanthus Garden. The Wenchang Pavilion is the core building of the garden area. The building on the axis is a place for literature and the Osmanthus Garden is a natural space for communication, which combines human and nature perfectly.

\subsection{Building Group Combination}

The plans of Chinese academies can be classified according to the form of courtyards (Hou, 2009). Thus, the combination of plans of Chinese academies can be divided into three types: walls enclosing courtyard, isles enclosing courtyard and buildings enclosing courtyard (Shao, 1997). Zhushan academy belongs to the second type. Important buildings are arranged on the central axis. The isles combine the buildings together and form courtyards. Therefore, the interior space is quite open and the isle space is permeable, in pursing of the intimacy with nature (Figure 6). Moreover, the layout is closely related to the local climate. The isles can prevent the exposure to the sun and rain effectively.

The elevation of the academy is well-proportioned. The lecture hall (Figure 7), buildings and pavilions are connected by the isles. As the isles are lower, other buildings are highlighted. As a result, the skyline of the academy is scattered randomly with innervation. The eaves of the buildings are not on the same straight line. Instead, different buildings are joined with courtyards or parapets, which make the academy more open and multi-leveled. 

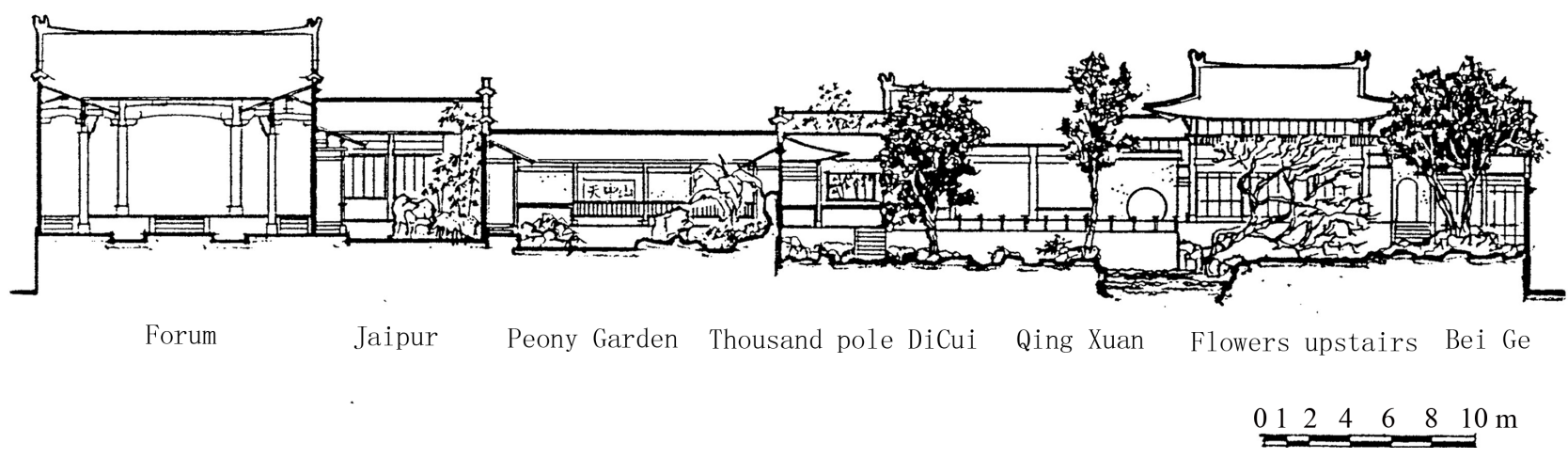

Figure 6. The section of the academy.

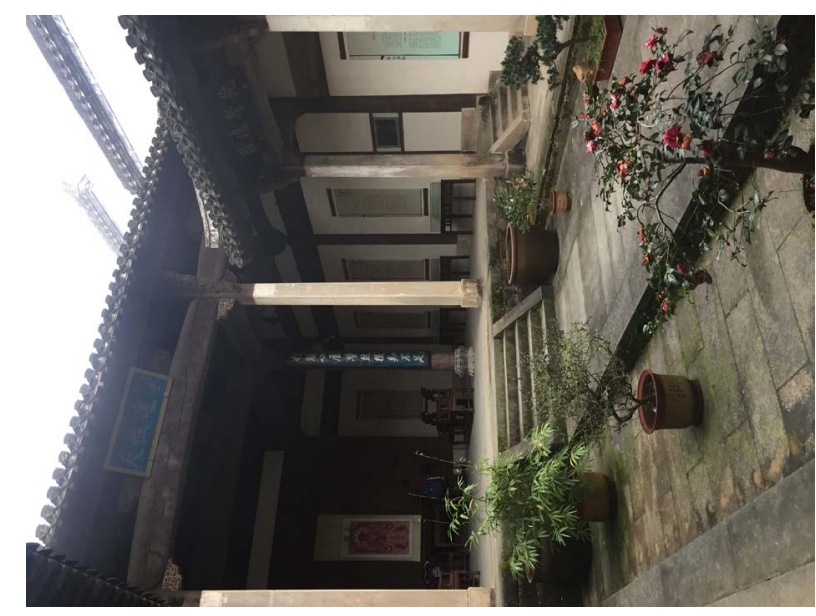

Figure 7. Lecture hall.

\subsection{Building Monomer}

The existing buildings in the academy were built in the Qing Dynasty. Except for the worship part, other buildings of the academy are decorated simple and elegant. The modelling technique absorbs the characteristics of folk dwellings, in pursuit of the beauty of nature (Kong \& Bai, 2011).

- The gate of the academy

The gate of the academy is the main entrance (Figure 8). It is a one floor one-floor one-single slope house facing to the east. The slope can lead the rainwater into the patio. The gate takes the form of archway and four Chinese characters of "Zhushan academy" are carved on it. Its depth is $4.6 \mathrm{~m}$ and its width is $12.1 \mathrm{~m}$.

- Lecture hall

Behind the gate is the lecture hall (Figure 9) and its patio. The floor of the lecture hall is $0.6 \mathrm{~m}$ higher than the isles'. There are stone stairs joining the isles and the patio with the lecture hall. There is a pair of couplet praising the bamboo. In Chinese culture, the bamboo symbolizes the modest character for its stalk is empty (Liang \& Ju, 2009). The couplet is set to encourage the students to dedicate to their study.

- Qingkuang Hall and the terrace 


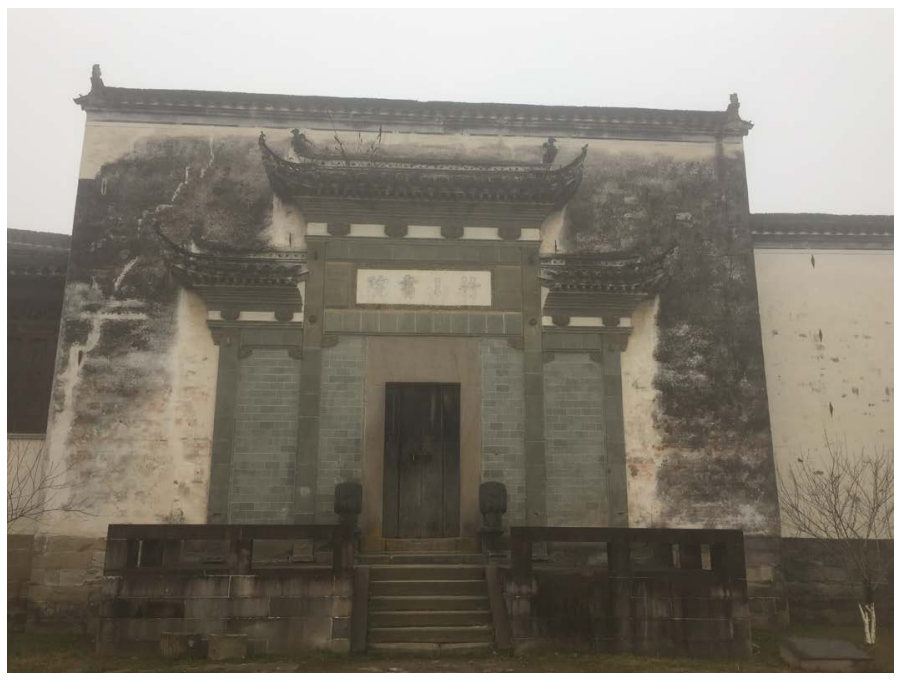

Figure 8. Gate of the academy.

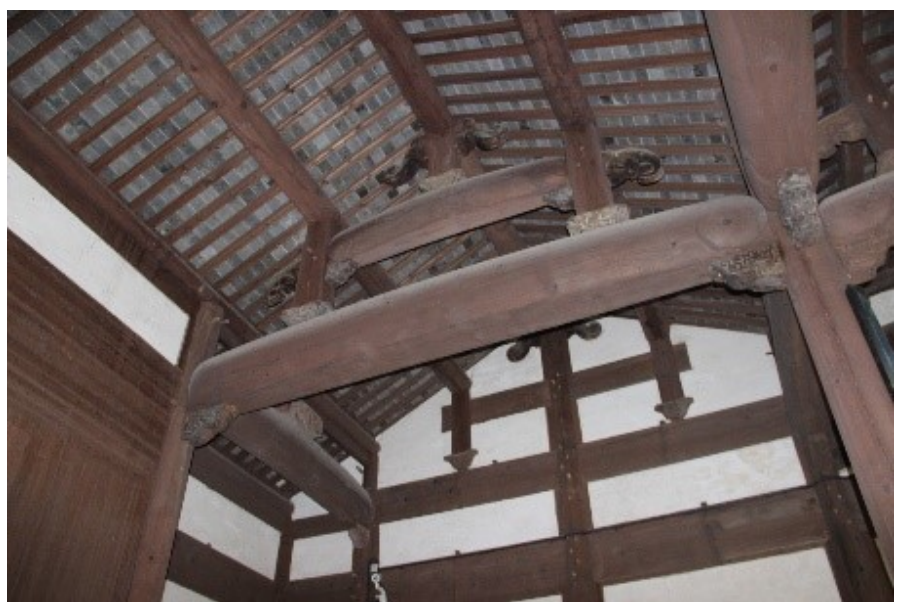

Figure 9. Interior of the lecture hall.

Qingkuang Hall (Figure 10 and Figure 11) is located in the east part of the Osmanthus Garden. It is one of the most important buildings in the garden area. Its main function is to provide a get-together space for the scholars. Its gable is a screen, which is good for sight viewing. Its width is $10 \mathrm{~m}$ and its depth is $9.5 \mathrm{~m}$.

There is a $35 \mathrm{~m}^{2}$ terrace under the eave of Qingkuang Hall. There are stone railings around the terrace with lion carvings, which is subtle and vivid.

- Wenchang Pavilion

Wenchang Pavilion (Figure 12 and Figure 13) is the main building in the Osmanthus Garden. It is in the north part of the Osmanthus Garden. The plan is octagon. The length of each side is about 2.9 meters and its height is $17.8 \mathrm{~m}$. Confucius is worshipped on the first floor and Wenchang Jun is worshipped on the second floor.

- Osmanthus Garden

Osmanthus Garden is a large courtyard enclosed by the buildings in the garden part (Figure 14). Anyone who succeeded in the imperial exam would plant an osmanthus tree in the courtyard. In Chinese culture, osmanthus means suc- 


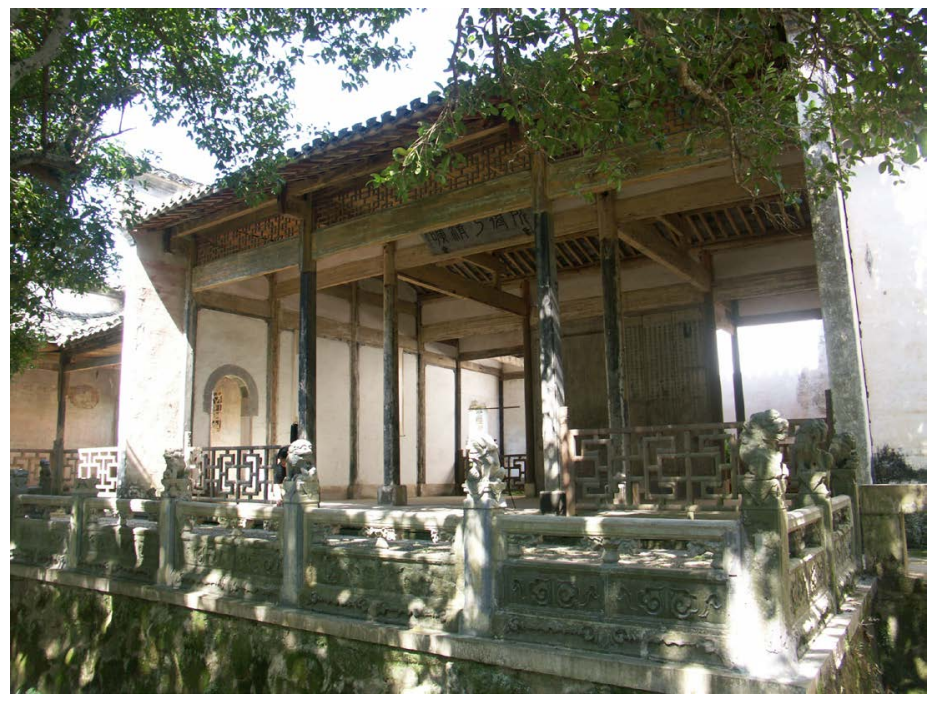

Figure 10. Qingkuang Hall.

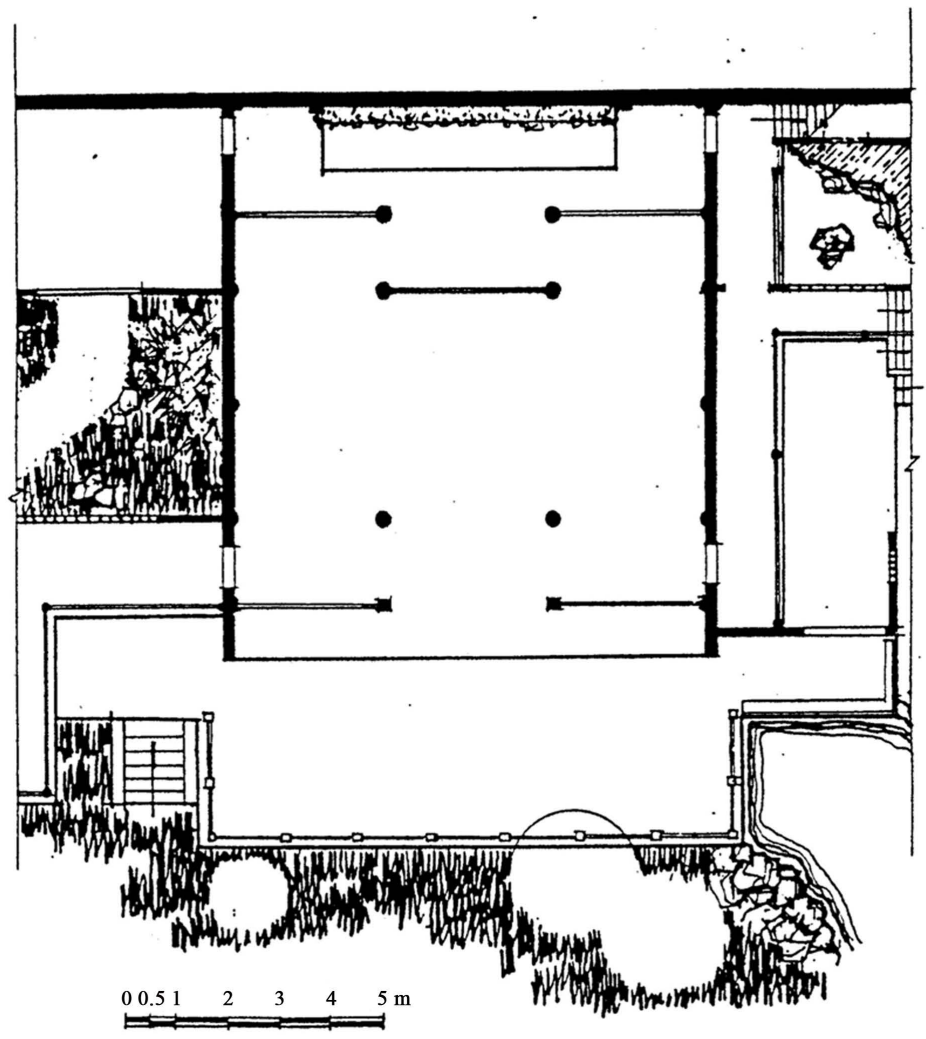

Figure 11. Plan of Qingkuang hall.

cessful. That is the origin of the name "Osmanthus Garden". The area of the garden is $650 \mathrm{~m}^{2}$. There are still 20 osmanthus trees and some other plants such as ginkgo trees in the garden. There used to be a big rockery in the garden, but now there are only several stones left. There is a little pool with the shape of an autumn leaf named Qiuye Pool. The water in the pool flows from the stone bridge before the Wenchang Pavilion to the east courtyard of the Osmanthus Garden. 


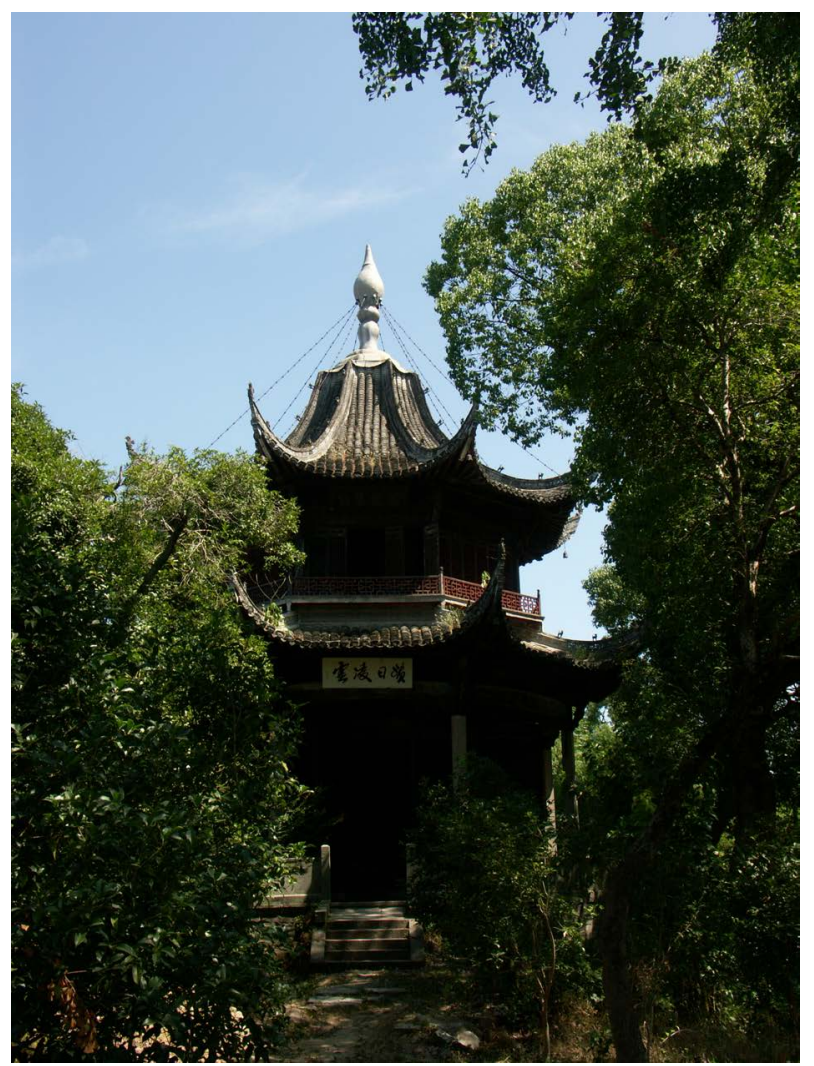

Figure 12. Wenchang Pavilion.

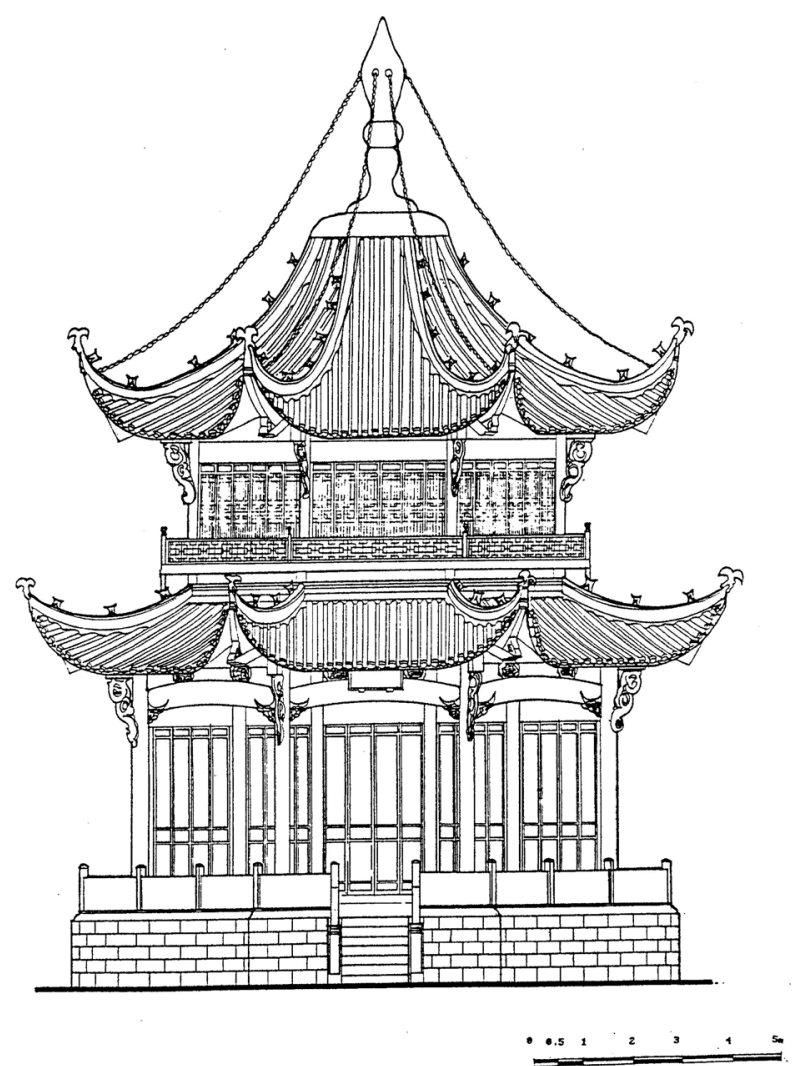

Figure 13. Elevation of Wenchang Pavilion. 


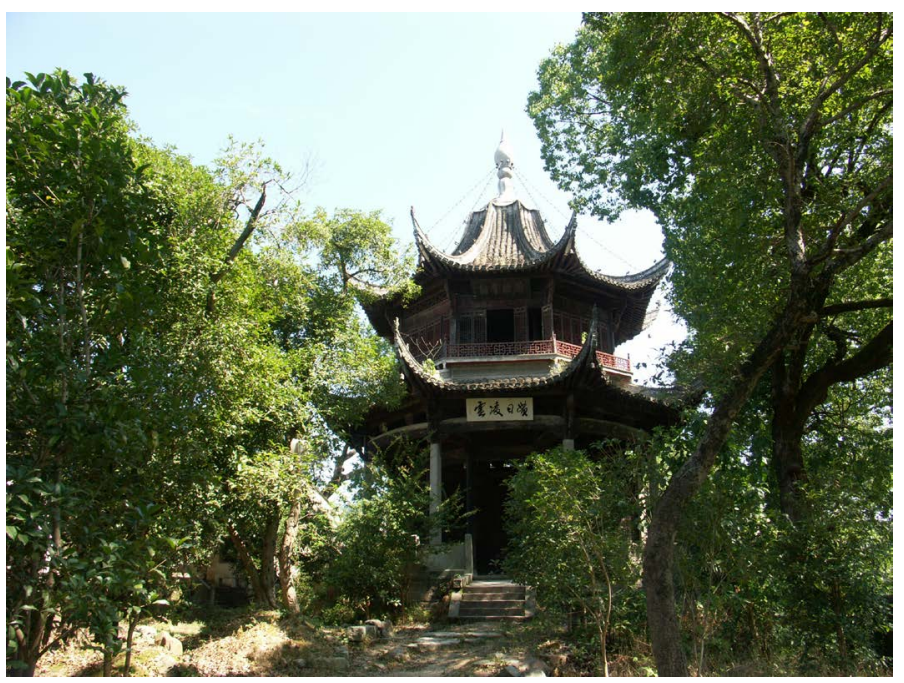

Figure 14. Osmanthus Garden.

\subsection{Poetic Imagery of Garden}

Due to the suitable site selection, we cannot feel the density of buildings, which represents the management of garden space has reached a high level. The garden of Zhushan academy (Figures 15-17) borrows the scenery of Jian River and Zhushan Mountain to make the garden space deeper. Moreover, the arrangement of rockery and pools makes the academy integrate with nature (Liang \& Ju, 2009). Besides, the garden uses poetic imagery as well. The plant of almond trees symbolizes teaching and the osmanthus represents successful in the imperial exam. The inscriptions on tablets and penmanship fuse with the atmosphere of the garden perfectly. The garden keeps the style of Song and Ming Dynasties, simple and natural. The buildings are decorated with brick, wood and stone carvings, inheriting the style of folk dwellings in Anhui Province.

\section{The Enlightenment on Modern Educational Buildings}

The folk academy is the wisdom crystallization of ancient Chinese. Thus, it still provides much enlightening guidance on modern educational buildings.

\subsection{Layout}

The campus space can adopt the layout of axial symmetry from a macro perspective. The main public teaching buildings should be arranged on the front of the axis with an open square to provide enough space to rest and evacuate. Other buildings such as the library should be placed at the end of the axis to create a quiet environment for study. Moreover, the application of courtyards with different levels is also advisable. The courtyard can create a cozy and quiet environment with ease, which is suitable for thinking and communication (Wang, 2005).

\subsection{Suitable Construction}

The respect for the local environment and drawing on local resources is the con- 


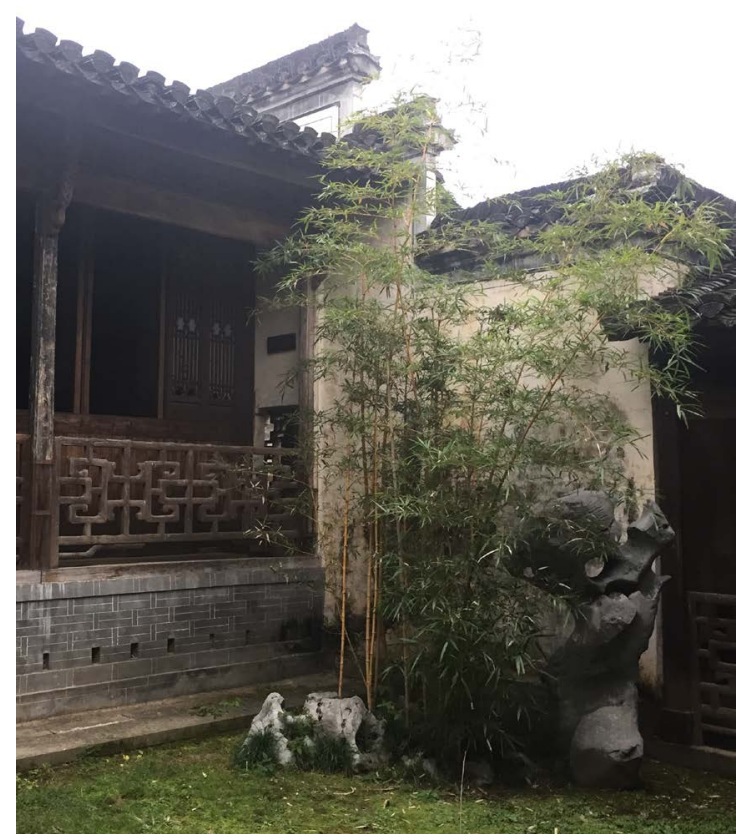

Figure 15. Poetic imagery I.

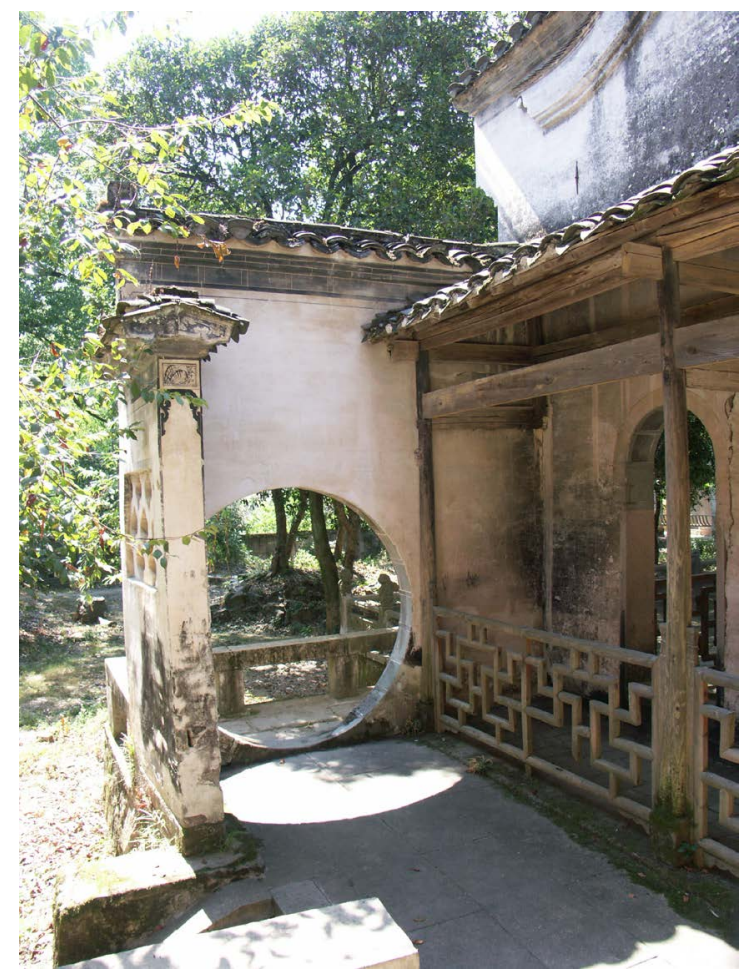

Figure 16. Poetic imagery II.

struction wisdom of folk academies. Sunshade, ventilation, lighting and other construction skills are applied in the academy design. Therefore, the space of the academy is rich in level, its appearance is simple and vivid, harmonious with nature (Cheng, 2002). As to the design modern educational buildings, the construction of folk academies is still worth studying. 


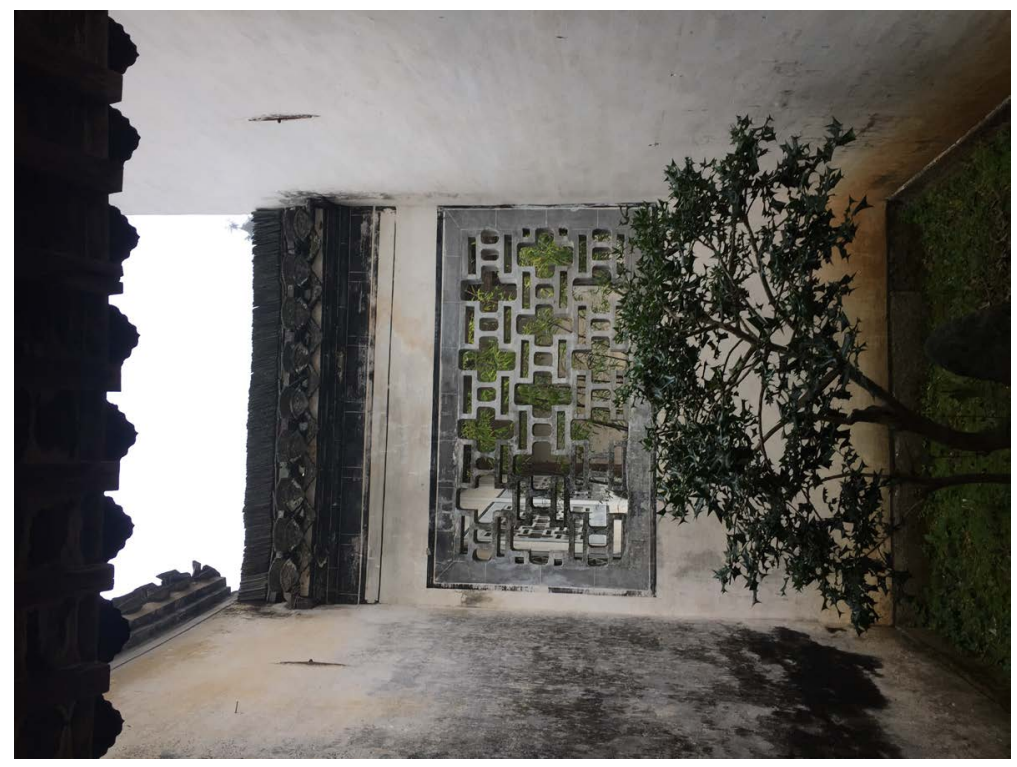

Figure 17. Poetic imagery III.

\subsection{Building Group Combination}

The arrangement of modern campus space can draw lessons from traditional Chinese culture to create an atmosphere of poetic imagery, such as the application of garden space (Yang, 2002). It can be said without exaggeration that learning from Chinese traditional architectural culture is an important source of inspiration for modern architecture design.

\section{Conclusion}

Zhushan Academy is an 18th century's architectural complex located in the Anhui Province, China. As a folk academy, it was built in strong link with the natural environment and with a balanced relationship with the other buildings of the village. Every architectural element and aspect of the construction has been studied to enhance the scholars' activities of study, meditation and dialog. The contribution analyzes the Academy characters and explains why it can be a reference model for modern architectural buildings.

\section{References}

Chen, J. L., \& Xiao, P. (2006). Influences of Classical Academy on the Construction of Modern Campus. New Architecture, 4, 61-66.

Cheng, J. Y. Huizhou Gardens. (2002). Journal of Huangshan University, 4, 34-38.

Hou, Y. B. (2009). Chinese Architectural Aesthetics. Beijing: China Building Industry Press.

Kong, S. M., \& Bai, X. (2011). Ancient Chinese Academy of Architectural Form: Four Chinese Academy of Ancient Case. Huazhong Architecture, 7, 177-180.

Liang, N. N., \& Ju, J. X. (2009). The Environment Characteristics and Cultural Connotation of Classical Academy Gardens in China-A Case Study on Zhushan Academy. Chinese Landscape Architecture, 3, 59-63.

Shao, G. L. (1997). Analysis on the Architectural Art of Zhushan Academy. Traditional 
Chinese Architecture and Gardens, 1, 42-43.

Wang, Z. Y. (2005). Scenic Spot of Academy and Garden: Xiong Village. Hefei: HeFei University of Technology Press.

Yang, S. C. (2002). Culture and Architecture of Chinese Academy. Wuhan: Hubei Education Publishing House.

Submit or recommend next manuscript to SCIRP and we will provide best service for you:

Accepting pre-submission inquiries through Email, Facebook, LinkedIn, Twitter, etc. A wide selection of journals (inclusive of 9 subjects, more than 200 journals)

Providing 24-hour high-quality service

User-friendly online submission system

Fair and swift peer-review system

Efficient typesetting and proofreading procedure

Display of the result of downloads and visits, as well as the number of cited articles Maximum dissemination of your research work

Submit your manuscript at: http://papersubmission.scirp.org/

Or contact adr@scirp.org 